\title{
Future perspectives of therapeutic monoclonal antibodies
}

\author{
Kanta Tsumoto ${ }^{1}$, Yushi Isozaki ${ }^{1}$, Hisanori Yagami ${ }^{2}$ \& Masahiro Tomita*,1 \\ ${ }^{1}$ Molecular Bioengineering Laboratory, Division of Chemistry for Materials, 1577 Kurima-Machiya-cho, Tsu, Mie 514-8507, Japan \\ ${ }^{2}$ Intelectual Property Office (IPO), Organization for the Promotion of Regional Innovation, 1577 Kurima-Machiya-cho, Tsu, Mie \\ 514-8507, Japan \\ *Author for correspondence: Tel.: +81 59231 9428; Fax: +81 59231 9430; tomita@chem.mie-u.ac.jp
}

\begin{abstract}
Attention to therapeutic monoclonal antibodies has been dramatically increasing year by year. Their highly specific targeting of antigens can provide very effective medical treatment, and the advent of moleculartargeting medicine is allowing development of a new generation of therapeutic agents. However, there is one critical obstacle to overcome. Most of the established therapeutic monoclonal antibodies have specificity for the primary structures of target antigens, although all proteins harbor original native intact structures for their own specific functions. Stereo-specific monoclonal antibodies recognizing conformational structures of target antigens may thus offer a markedly more versatile approach. Their application may change the very concepts underlying use of therapeutic antibodies.
\end{abstract}

First draft submitted: 31 August 2018; Accepted for publication: 31 October 2018; Published online: 11 January 2019

Keywords: antigen-expressing myeloma cell $\bullet$ B-cell receptor $(B C R) \bullet$ conformational epitope $\bullet$ DNA immunization - hybridoma technology $\bullet$ native structure $\bullet$ stereo-specific monoclonal antibody $\bullet$ therapeutic medicine

\section{Therapeutic monoclonal antibodies}

The biopharmaceutical market, like the global pharmaceutical market, has been expanding every year and is expected to reach approximately 230 billion dollars in 2018 , twice the sum in 2010 [1]. It is forecasted to be $>380$ billion dollars in 2024 [1]. Recombinant proteins, followed by therapeutic antibodies, have been the main contributors to the biopharmaceutical market in the past. However, in 2017 [2] the sales of antibody-based medicines took on the leading position, with expected sales of 172.8 billion dollars in 2022, about $20 \%$ of the global pharmaceutical market [2].

It is noteworthy that the range of therapeutic monoclonal antibodies has been remarkably increasing since the late 1990s, the total number approved by the US FDA reaching 64 in 2018 [2,3] (see Table 1 list for those from 2015 to 2017). In 2017, a total of 11 therapeutic monoclonal antibodies were approved. There are interesting changes in the characteristics of the antibodies attracting attention. As shown in Figure 1, the percentage of human and humanized antibodies in the total has dramatically increased. The reasons for continuous expansion of the market for therapeutic antibodies include an increase in the number of approvals, efforts to explore other target diseases for the already approved therapeutic antibodies, as well as improvements in formulations and dosage forms. Finding new target antigens will be of critical importance for further development of antibody-based medicines in the future.

Bispecific antibodies [6-10], antibody-drug conjugates [11], sugar chain-modified antibodies [12-15] and low molecular weight antibodies $[6,16]$ are now being emphasized as next-generation products. Some bispecific antibodies and antibody-drug conjugates are already on the market, with emicizumab [17] as an example of the former, and gemtuzumab ozogamicin [18], inotuzumab ozogamicin [19] and brentuximab vedotin [20] featuring in the latter.

\section{Advantages of stereo-specific monoclonal antibodies}

There is another important point regarding further development of therapeutic monoclonal antibodies. A critical reason for their employment is their high specificity and affinity for targeted antigens. It is known that monoclonal antibodies can specifically recognize two types of epitopes (Figure 2). One is linear in the primary structures of 
Table 1. The US FDA-approved therapeutic monoclonal antibodies from 2015 to 2017. 27 therapeutic monoclonal antibodies were approved by the US FDA from 2015 to 2017. The number has been increasing year by year.

\begin{tabular}{|c|c|c|c|c|}
\hline Name of antibody & Brand name & Approved year & Target antigen & Target disease \\
\hline Dinutuximab & Unituxin ${ }^{\circledR}$ & 2015 & GD2 & Pediatric high-risk neuroblastoma \\
\hline Idarucizumab & Praxbind $^{\circledR}$ & 2015 & Dabigatran & $\begin{array}{l}\text { Emergency reversal of } \\
\text { anticoagulant dabigatran }\end{array}$ \\
\hline Elotuzumab & Empliciti ${ }^{\circledR}$ & 2015 & SLAMF7 & Multiple myeloma \\
\hline Nivolumab & Opdivo ${ }^{\circledR}$ & 2015 & PD-1 & Metastatic melanoma \\
\hline Alirocumab & Praluent ${ }^{\circledR}$ & 2015 & PCSK9 & $\begin{array}{l}\text { Heterozygous familial } \\
\text { hypercholesterolemia, } \\
\text { Refractory hypercholesterolemia }\end{array}$ \\
\hline Necitumumab & Portrazza ${ }^{\circledR}$ & 2015 & EGFR & $\begin{array}{l}\text { Metastatic squamous } \\
\text { non-small-cell lung carcinoma }\end{array}$ \\
\hline Ixekizumab & Taltz $^{\circledR}$ & 2016 & IL-17A & Plaque psoriasis \\
\hline Reslizumab & Cinqair $^{\circledR}$ & 2016 & IL-5 & Severe asthma \\
\hline Atezolizumab & Tecentriq $^{\circledR}$ & 2016 & PD-L1 & Urothelial carcinoma \\
\hline Olaratumab & Lartruvo $^{\circledR}$ & 2016 & PDGFR & Soft tissue sarcoma \\
\hline Bezlotoxumab & Zinplava ${ }^{\circledR}$ & 2016 & Clostridium difficile toxin B & $\begin{array}{l}\text { Prevent recurrence of } C \text {. difficile } \\
\text { infection }\end{array}$ \\
\hline Gemtuzumab ozogamicin & Mylotarg ${ }^{(\mathbb{R}}$ & 2017 & CD33 & Acute myeloid leukemia \\
\hline Ocrelizumab & Ocrevus $^{\circledR}$ & 2017 & $\mathrm{CD} 20$ & Multiple sclerosis \\
\hline Inotuzumab ozogamicin & Besponsa ${ }^{\circledR}$ & 2017 & $\mathrm{CD} 22$ & $\begin{array}{l}\text { Precursor B-cell acute } \\
\text { lymphoblastic leukemia }\end{array}$ \\
\hline Emicizumab & Hemlibra $^{\circledR}$ & 2017 & FIXa, FX & $\begin{array}{l}\text { Hemophilia A (congenital Factor } \\
\text { VIII deficiency) with Factor VIII } \\
\text { inhibitors }\end{array}$ \\
\hline Dupilumab & Dupixent ${ }^{\circledR}$ & 2017 & IL-4R $\alpha$ & Atopic dermatitis \\
\hline Guselkumab & Tremfya $^{\circledR}$ & 2017 & IL-23 & Plaque psoriasis \\
\hline Sarilumab & Kevzara ${ }^{\circledR}$ & 2017 & IL-6R $\alpha$ subunit & Rheumatoid arthritis \\
\hline
\end{tabular}

proteins. The other is conformational, dependent on secondary and tertiary structures. In addition to their primary, secondary and tertiary structures, proteins may also exhibit quarterly structures formed by hetero- or homosubunits, which provide unique interfacial geometries on their complexes. Intact native proteins mainly feature secondary and tertiary structures, but various kinds of monoclonal antibodies do not necessarily have specificity for conformational structures, although they have been raised against a large number of proteinous antigens.

Such specific recognition of conformational structures of proteins would be expected to give more strict selectivity and affinity for therapeutic purposes. Notably, stereo-specific monoclonal antibodies recognizing 3D configurations of molecules, offer advantages over linear epitope-specific monoclonal antibodies, which only recognize 2D configuration. Again we should stress that target antigens for therapy predominantly feature secondary and tertiary structures. Monoclonal antibodies recognizing primary structures can have affinity for only restricted regions in intact antigens, because linear epitopes can be masked by conformational folding. Thus, the employment of stereo-specific monoclonal antibodies should be our goal. 


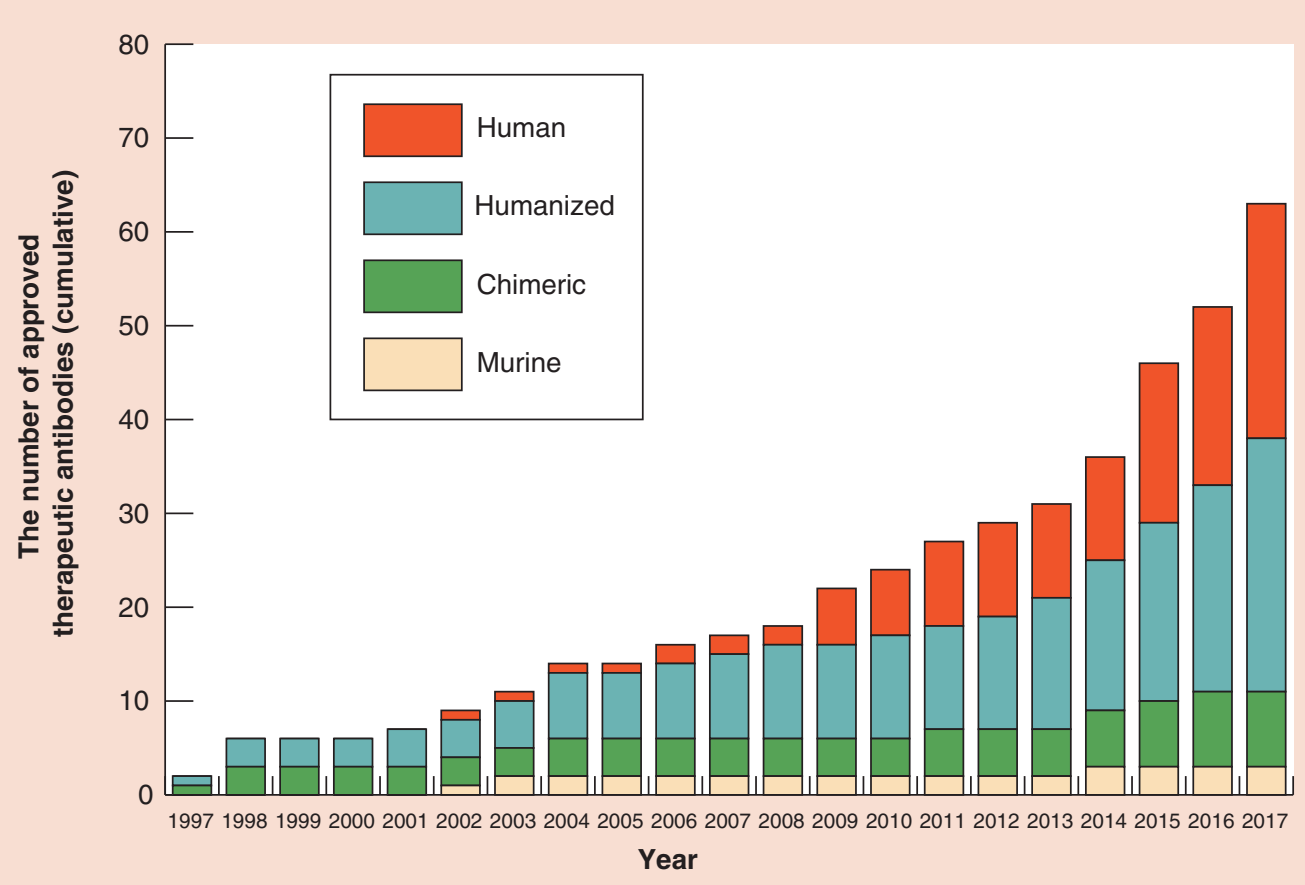

Figure 1. The US FDA-approved therapeutic monoclonal antibodies. 64 therapeutic monoclonal antibodies have been approved by the US FDA. The ratio of human and humanized monoclonal antibodies to the total sum of therapeutic monoclonal antibodies is increasing year by year.

\section{Production of stereo-specific monoclonal antibodies against different proteins}

The next point is how to produce stereo-specific monoclonal antibodies. Until very recently, no practical technologies have been available for their generation, because of difficulties like how to immunize a mouse maintaining the structure of the antigen intact in the presence of adjuvant. While adjuvants generally allow more effective sensitization, they usually disrupt the original protein native structure. If an adjuvant is not used, immunization efficiency may be very low. Another difficulty is strict selection of sensitized B lymphocytes secreting stereo-specific monoclonal antibodies. Even when immunization is successful with a native intact antigen, the number of desired sensitized B lymphocytes is usually extremely small, accounting for only a few percent of the total spleen cells after repeated immunization.

However, we have now established an original stereo-specific targeting (SST) technique [21-25]. The protocol promises efficient generation of stereo-specific monoclonal antibodies on the basis of hybridoma technology, as illustrated in Figure 3. One of the critical points is strict selection of the required sensitized B lymphocytes by intact antigens expressed on myeloma cells through B-cell receptors (BCRs). This precise selection also enables efficient formation of B-cell and myeloma-cell complexes for generating hybridoma cells secreting the aimed for antibodies.

In general, proteins are divided into two categories, membrane associated and nonassociated. The former include receptors, membrane-anchored proteins and so on, whereas the latter are mainly soluble proteins present in intraand intercellular spaces, as shown in Figure 4. Regardless of which types of proteins are used, the important point for raising stereo-specific monoclonal antibodies is that the target antigens have to be recognized by the immune system while retaining native structures. For this purpose, the best method is DNA immunization to maintain intact conformational structures. It is recommended that target antigens be expressed on the surface of cells, because this location facilitates stable exhibition of intact conformational structures to the immune system. With soluble proteins, they can be tethered to membranes to mimic membrane proteins. Appropriate signal peptide and a membrane-penetrating domains are genetically attached in frame as nucleic acid sequences to the $5^{\prime}$ - and $3^{\prime}$-terminals, respectively, of the genes for the desired soluble proteins so that they are expressed together.

The next point is the selection of sensitized B lymphocytes, where use of antigen-expressing myeloma cells seems to be the best option. There are several advantages. DNA-immunized B lymphocytes can be efficiently selected by a target intact antigen expressed on myeloma cells by harnessing strong and specific interactions between intact 


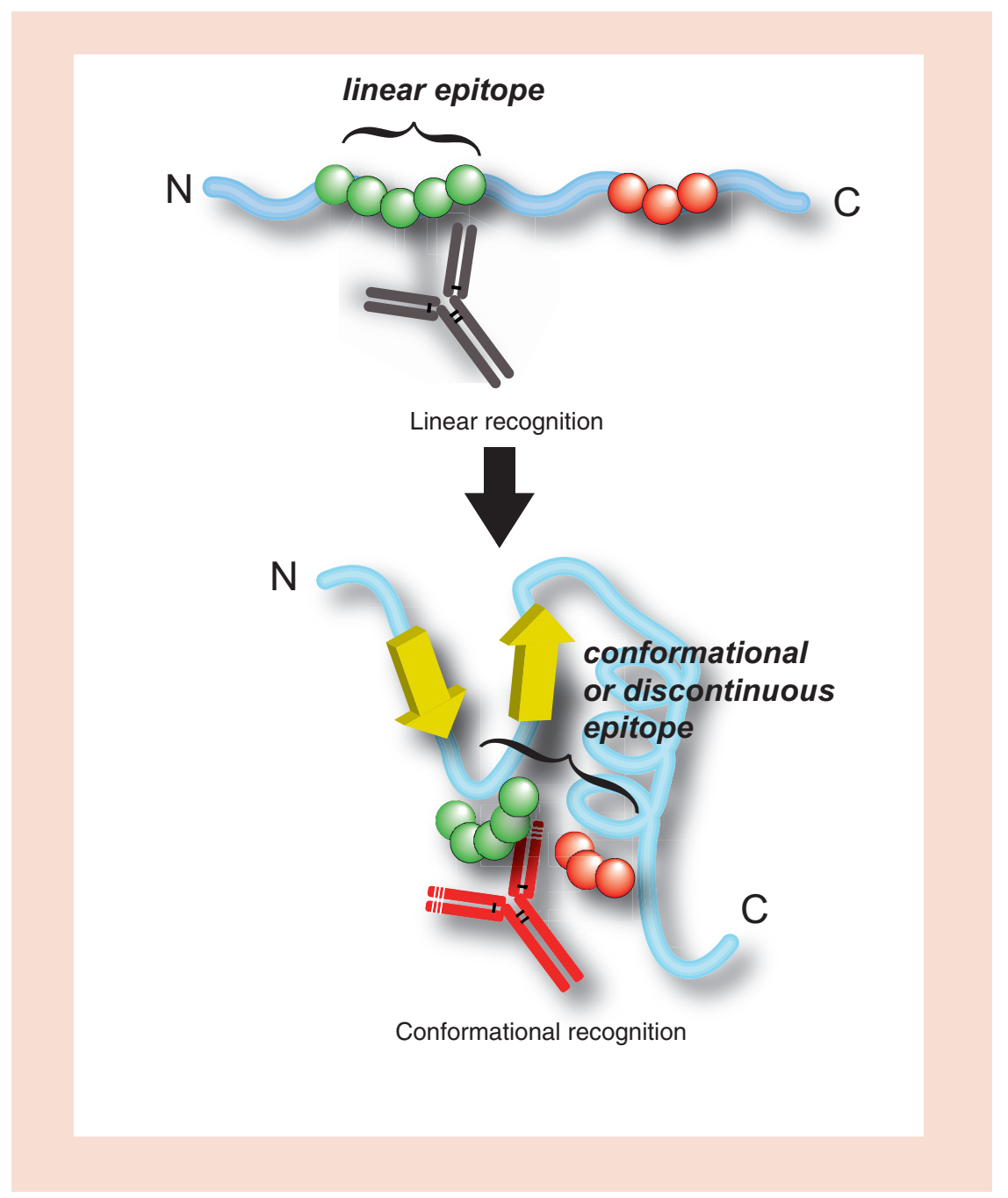

Figure 2. Two types of epitopes. Epitope recognition by antibodies is generally divided into two types. One is linear epitope-specific recognition and the other is conformational or discontinuous epitope specific.

antigen and antibody (BCR). The antigens expressed on the myeloma cells must clearly keep their original intact structures. In this step, only B lymphocytes secreting stereo-specific monoclonal antibodies directed to the target antigens can be preferentially selected. Moreover, selected B lymphocytes combined together with myeloma cells have another advantage, since they can be selectively fused by electrical pulses to generate hybridoma cells secreting the desired stereo-specific monoclonal antibodies. Indeed, fusion by electric field is very specific, due to the fact that only attached cells can be selectively fused. B lymphocytes selected by antigen-expressing myeloma cells are preferentially fused without causing any undesired fusion among other unattached cells. Thus, successful generation of stereo-specific monoclonal antibodies is based on DNA immunization, selection of sensitized B lymphocytes by antigen-expressing myeloma cells and selective fusion of the B cell-myeloma cell complexes by electrical pulses.

As already noted, the SST technique features selective generation of stereo-specific monoclonal antibodies against various kinds of proteins for not only membranous antigens, but also nonmembranous soluble ones (Figure 4). Recently, Morshed et al. have shown that a stereo-specific monoclonal antibody was effective for activating the G-protein coupled receptor, which harbors seven transmembrane domains [26].

\section{Conclusion}

Critical points for employing monoclonal antibodies as therapeutic agents are their strict specificity and strong affinity for target antigens. From this viewpoint, conformational epitope-specific monoclonal antibodies offer clear advantages over conventional linear epitope-specific examples, since they maintain the original secondary and 
Figure 3. Flowchart of stereo-specific targeting. DNA-immunized B lymphocytes are selected by antigen-expressing myeloma cells, followed by selective fusion by electrical pulses to generate hybridoma cells that can secrete stereo-specific monoclonal antibodies.

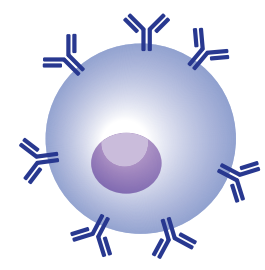

B cell

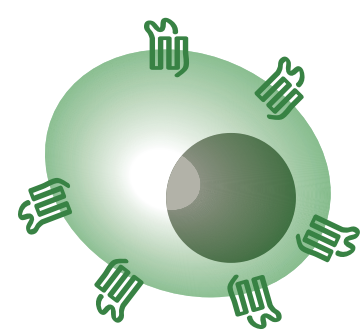

Myeloma cell
Stereospecific targeting (SST)

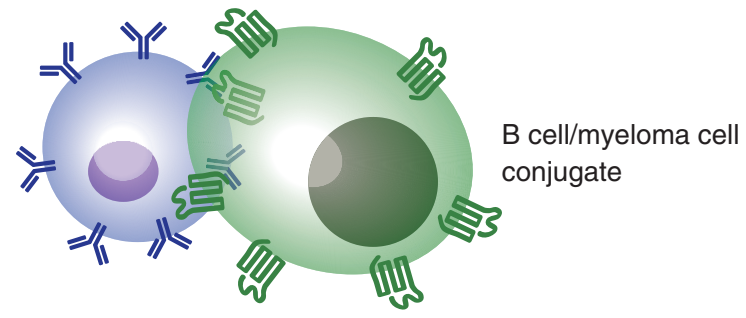

Electrical pulses for membrane fusion

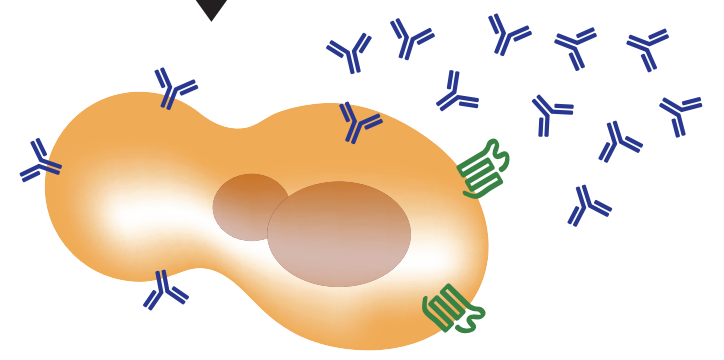

Hybridoma cell

tertiary structures, which intrinsically determine their biological functions. Our new technology termed 'SST' features selective generation of conformation-specific monoclonal antibodies with high specificity and affinity. Characteristic is the use of strong and specific interactions between BCRs and intact antigens on myeloma cells. SST may also be applicable for new types of bispecific as well as catalytic antibodies. The new technology could greatly contribute to next-generation therapeutic medicine.

\section{Future perspective}

\section{New types of bispecific antibody}

Bispecific antibodies can recognize two distinct antigens, and have already been developed and used as therapeutic agents for carcinomas, leukemia and hemophilia [27-29]. To develop novel therapeutic bispecific antibodies, it is crucial to identify combinations of target molecules, which are appropriate for producing high-potency antibodies. The enzyme-mediated activation of radical source (EMARS) method reported by Kotani et al. is a technology to analyze bi-molecular complexes (hetero-protein complexes) formed on cell membranes under physiological conditions [30] and is also applicable to identifying cancer cell-specific bi-molecular complexes for preparing therapeutic bispecific antibodies against cancer cells. Since combinations of molecules are theoretically almost infinite, this might help overcome the current difficulty of finding candidate antigens in exploring novel therapeutic approaches. 


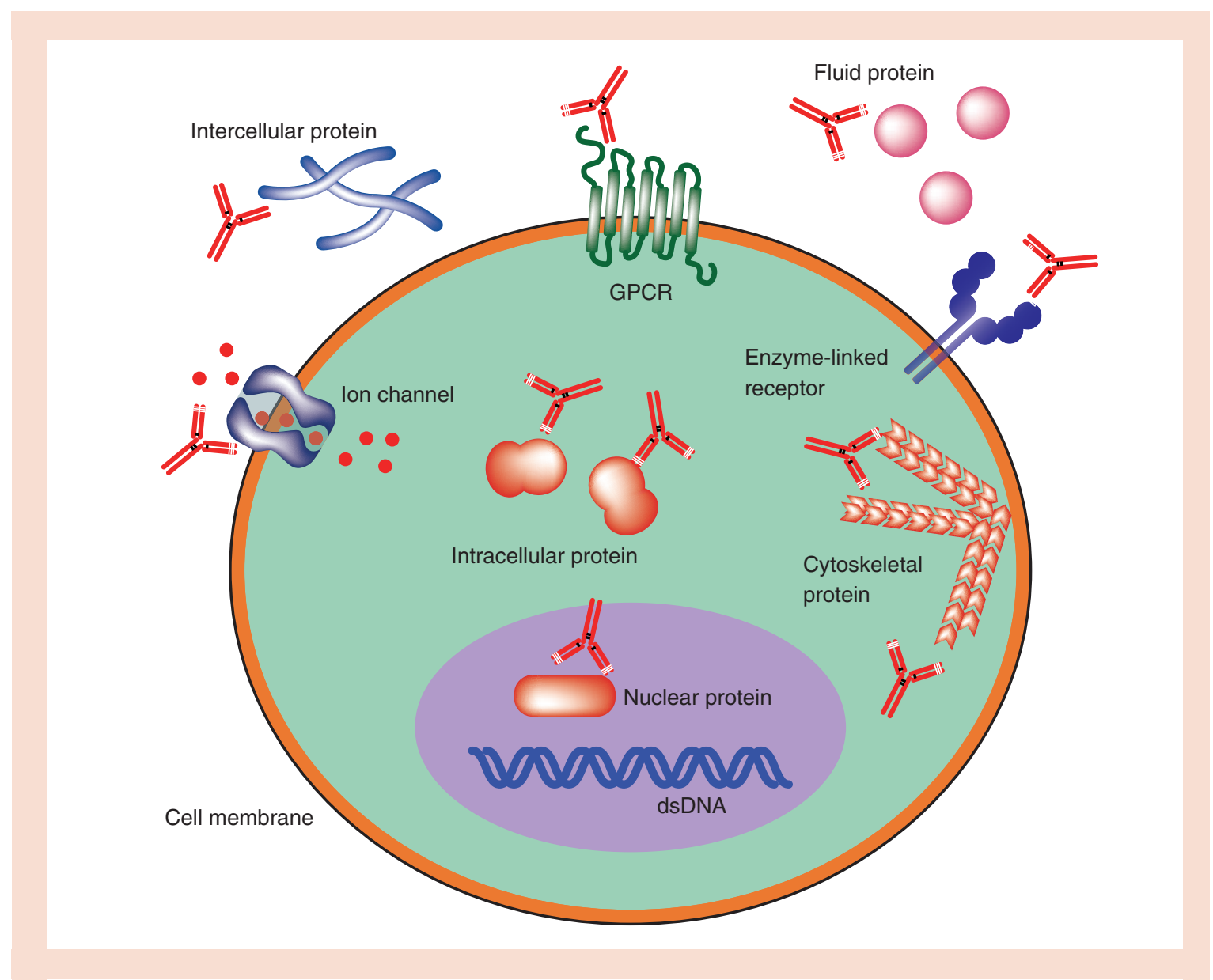

Figure 4. Generation of stereo-specific monoclonal antibodies against all kinds of native proteins. Theoretically, the stereo-specific targeting technique is applicable to generating stereo-specific monoclonal antibodies against all kinds of native proteins. There are three critical steps: DNA immunization; selection of sensitized B lymphocytes by antigen-expressing myeloma cells; and selective fusion of B-cell and myeloma-cell complexes to generate hybridoma cells secreting stereo-specific monoclonal antibodies.

Bispecific monoclonal antibodies harboring stereo-specific recognition may be particularly effective for detecting membranous antigens on cancer cells, which are not easily recognized with conventional linear-specific monoclonal antibodies. Another potential advantage could be recognition of unique conformational structures lying in heteroprotein complexes, in addition to possible individual reactions with pairs of heteroantigens. Thus, detection of bi-molecular complexes as single molecular elements is conceivable, as shown in Figure 5.

\section{New catalytic antibodies}

Another application of stereo-specific monoclonal antibody might be as catalytic agents. Recent extensive studies on catalytic antibodies have advanced so that practical applications are now on the horizon. As catalytic antibodies possess the ability not only to recognize but also to degrade antigens, they may exhibit unique characteristics superior to monoclonal antibody drugs. The Uda/Hifumi group has already demonstrated that the mouse-type catalytic antibody light chain could eradicate Helicobacter pylori infection in the mouse stomach [31]. The same group also succeeded in suppression of infection with the rabies virus [32] and the influenza virus [33] in vitro and in vivo using human antibody light chains. On the other hand, Paul's group reported very interesting catalytic antibody capable of reducing the $\beta$-amyloid accumulated in the mice brain [34,35]. The catalytic antibody specifically hydrolyzes the target antigen at site-specific recognition. We would also propose that recognition of stereo-specific epitopes by stereo-specific monoclonal antibodies may provide more specific and effective hydrolysis of aimed intact antigens on the cell membranes for new therapeutic medicine (Figure 5), if catalytic activity can be introduced thereto. 


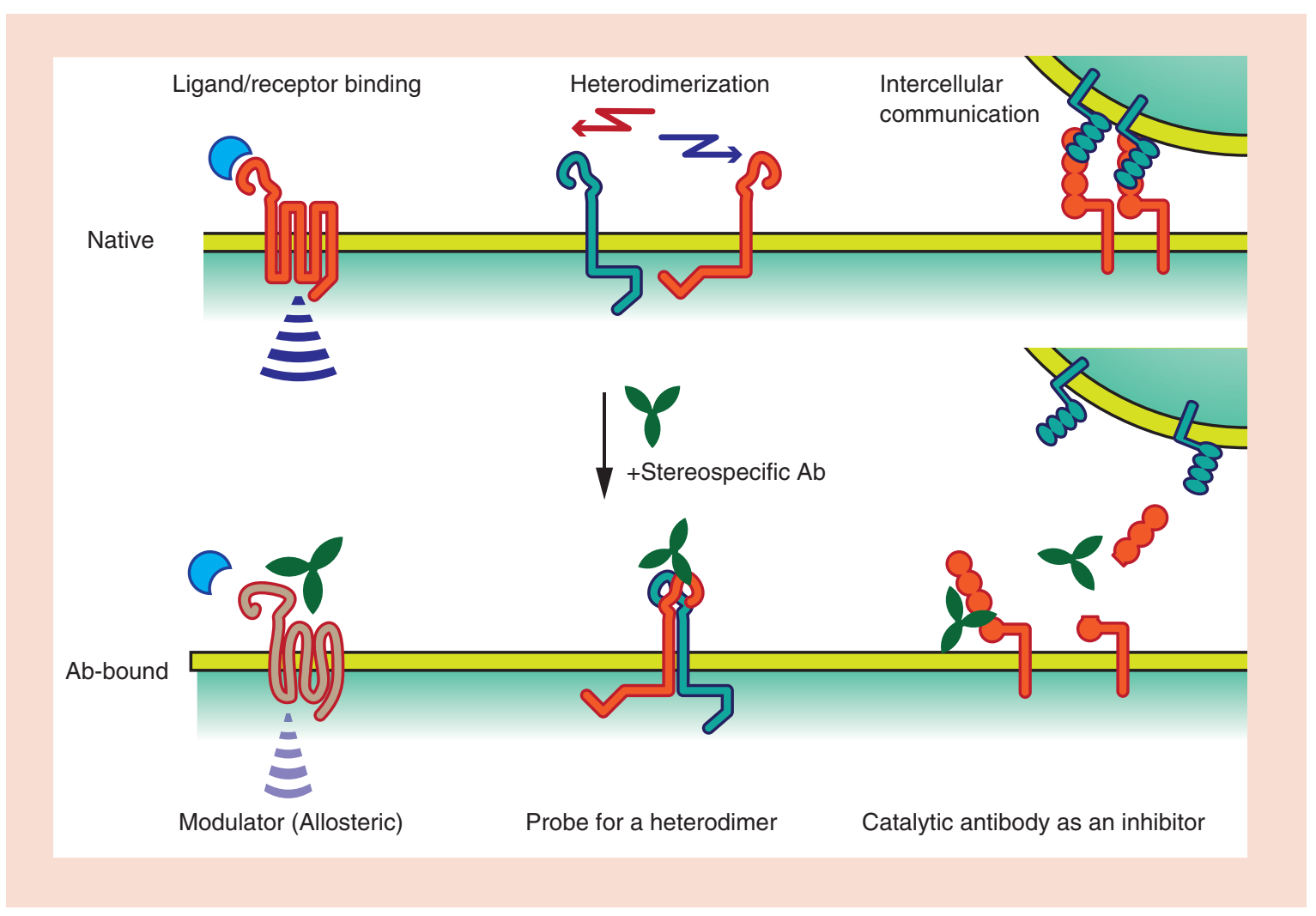

Figure 5. Advantages for conformational recognition. Recognizing conformational structures of intact proteins confers several advantages, promising therapeutic approaches to new regulation of functions of both mono- and multi-mer receptors, as well as novel bispecific and catalytic monoclonal antibodies.

\section{New type of specificity}

It is generally accepted that it is difficult to produce monoclonal antibodies against mouse antigens due to immune tolerance when mice are employed as immunization animals. This hampers analysis of disease-related important antigens in the mouse, a very good candidate model animal for many diseases. From the viewpoint of stereospecific recognition, however, it is possible to cross-react with antigen in other species by recognizing common conformational structures. This has never been reported with linear epitope-specific monoclonal antibodies.

\section{Executive summary}

\section{Therapeutic monoclonal antibodies}

- The market for therapeutic monoclonal antibodies is increasing year by year.

- Characteristics of therapeutic stereo-specific monoclonal antibodies are high specificity and affinity for target antigens.

Recognition of conformational epitopes

- General monoclonal antibodies show specific affinity to primary structures of target antigens through 2D recognition.

- Stereo-specific monoclonal antibodies show strict specificity to secondary and tertiary structures of target antigens by $3 \mathrm{D}$ recognition.

Future therapeutic medicines

- Stereo-specific targeting may contribute to selective production of stereo-specific monoclonal antibodies.

- Stereo-specific recognition of target antigens may provide novel therapeutic approaches, since proteins retain intact conformational structures in nature.

- Stereo-specific targeting may also be applicable to new types of bispecific and catalytic antibodies. 


\section{Acknowledgments}

The authors would like to thank T Matsuba for his contribution to stereo-specific targeting. Critical reading of the manuscript by $\mathrm{M}$ Moore is also appreciated.

\section{Financial \& competing interests disclosure}

This work was supported in part by JSPS KAKENHI grant numbers JP24360339, JP25630376, JP17H03468; and Tosoh Corporation. The authors have no other relevant affiliations or financial involvement with any organization or entity with a financial interest in or financial conflict with the subject matter or materials discussed in the manuscript apart from those disclosed. No computerized writing assistance was utilized in the production of this manuscript.

Ethical conduct of research

All experiments were conducted according to Mie University's guidelines for the care and treatment of experimental animals.

\section{References}

Papers of special note have been highlighted as: • of interest; $\bullet \bullet$ of considerable interest

1. EvaluatePharma. EvaluatePharma World Preview 2017, Outlook to 2022. EvaluatePharma World Preview 2018, Outlook to 2024. www.evaluategroup.com/

2. Akabane H. Issues of the biopharmaceutical industry and recommendations for further development. No. 71. Series of research paper (2018). www.jpma.or.jp/opir/research/rs_071/paper_71.pdf

3. National Institute of Health Sciences Division of Biological Chemistry and Biologicals. Approved antibody drugs in Japan, US and Europe. www.nihs.go.jp/dbcb/mabs.html

4. US FDA. www.fda.gov/default.htm

5. Wikipedia. Monoclonal antibody therapy. en.wikipedia.org/wiki/Monoclonal_antibody_therapy

6. Asano R, Nakayama M, Kawaguchi $\mathrm{H}$ et al. Construction and humanization of a functional bispecific EGFR $\times$ CD16 diabody using a refolding system. FEBS J. 279(2), 223-233 (2012).

7. Carlring J, De Leenheer E, Heath AW. A novel redox method for rapid production of functional bi-specific antibodies for use in early pilot studies. PLoS ONE 6(7), e22533 (2011).

8. Satt A, Mezzanzanica D, Caroli F et al. Design, selection and optimization of an anti-TRAIL-R2/anti-CD3 bispecific antibody able to educate T cells to recognize and destroy cancer cells. MAbs doi:10.1080/19420862.2018.1494105 (2018) (Epub ahead of print).

9. Asano R, Kuroki Y, Honma $S$ et al. Comprehensive study of domain rearrangements of single-chain bispecific antibodies to determine the best combination of configurations and microbial host cells. MAbs doi:10.1080/19420862.2018.1476815 (2018) (Epub ahead of print).

10. Li J, Ybarra R, Mak J et al. IFN- $\gamma$-induced chemokines are required for CXCR3-mediated T cell recruitment and anti-tumor efficacy of anti-HER2/CD3 bispecific antibody. Clin. Cancer Res. doi:10.1158/1078-0432.CCR-18-1139 (2018) (Epub ahead of print).

11. Smith I, Procter M, Gelber RD et al. 2-year follow-up of trastuzumab after adjuvant chemotherapy in HER2-positive breast cancer: a randomized controlled trial. Lancet 369(9555), 29-36 (2007).

12. Yamane-Ohnuki N, Kinoshita S, Inoue-Urakubo M et al. Establishment of FUT8 knockout Chinese hamster ovary cells: an ideal host cell line for producing completely defucosylated antibodies with enhanced antibody-dependent cellular cytotoxicity. Biotechnol. Bioeng. 87(5), 614-622 (2004).

13. Busse WW, Katial R, Gossage D et al. Safety profile, pharmacokinetics, and biologic activity of MEDI-563, an anti-IL-5 receptor $\alpha$ antibody, in a Phase I study of subjects with mild asthma. J. Allergy Clin. Immunol. 125(6), 1237-1244.e2 (2010).

14. Yamamoto K, Utsunomiya A, Tobinai K et al. Phase I study of KW-0761, a defucosylated humanized anti-CCR4 antibody, in relapsed patients with adult T-cell leukemia-lymphoma and peripheral T-cell lymphoma. J. Clin. Oncol. 28(9), 1591-1598 (2010).

15. Ishida T, Joh T, Uike N et al. Defucosylated anti-CCR4 monoclonal antibody (KW-0761) for relapsed adult T-cell leukemia-lymphoma: a multicenter Phase II study. J. Clin. Oncol. 30(8), 837-842 (2012).

16. Ferrara N, Damico L, Shams N, Lowman H, Kim R. Development of ranibizumab, an anti-vascular endothelial growth factor antigen binding fragment, as therapy for neovascular age-related macular degeneration. Retina 26(8), 859-870 (2006).

17. Oldenburg J, Mahlangu JN, Kim B et al. Emicizumab prophylaxis in hemophilia A with inhibitors. N. Engl. J. Med. 377(9), 809-818 (2017).

18. Jen EY, Ko CW, Lee JE et al. FDA approval: gemtuzumab ozogamicin for the treatment of adults with newly diagnosed CD33-positive acute myeloid leukemia. Clin. Cancer Res. 24(14), 1-5 (2018).

19. Choudhry A, O’Brien SM. Inotuzumab ozogamicin for the treatment of patients with acute lymphocytic leukemia. Drugs Today (Barc). 53(12), 653-665 (2017). 
20. de Claro RA, McGinn K, Kwitkowski V et al. US Food and Drug Administration approval summary: brentuximab vedotin for the treatment of relapsed Hodgkin lymphoma or relapsed systemic anaplastic large-cell lymphoma. Clin. Cancer Res. 18(21), 5845-5849 (2012).

21. Tomita M, Hirano M, Watanabe $\mathrm{E}$ et al. A new technology for intact antigen-based and receptor-mediated generation of novel monoclonal antibodies. Hum. Antibodies 16(1-2), 40-41 (2007).

22. Tomita M, Tsumoto K. New hybridoma technology based on antigen-specific immunoglobulin receptors. FEBS J. 277(Suppl. 1), 50 (2010).

23. Tomita M, Tsumoto K. Hybridoma technologies for antibody production. Immunotherapy 3(3), 371-380 (2011).

\section{-. A review article for the next generation of hybridoma technology.}

24. Yagami H, Kato H, Tsumoto K, Tomita M. Monoclonal antibodies based on hybridoma technology. Pharm. Pat. Analyst 2(2), 249-263 (2013).

25. Tsumoto K, Isozaki Y, Tomita M. 25.6 Production of monoclonal antibodies. In: Culture of Animal Cells: A Manual of Basic Technique and Specialized Applications (7th Edition). Freshney RI (Ed.). Willey Blackwell, Hoboken, NJ, USA, 544-545 (25. Supplementary Material 102-113) (2016).

26. Morshed SA, Ma R, Latif R, Davies TF. Biased signaling by thyroid-stimulating hormone receptor-specific antibodies determines thyrocyte survival in autoimmunity. Sci. Signal.doi:10.1126/scisignal.aah4120 (2018) (Epub ahead of print).

27. Löffler $\mathrm{A}$, Gruen $\mathrm{M}$, Wuchter $\mathrm{C}$ et al. Efficient elimination of chronic lymphocytic leukaemia $\mathrm{B}$ cells by autologous $\mathrm{T}$ cells with a bispecific anti-CD19/anti-CD3 single-chain antibody construct. Leukemia 17(5), 900-909 (2003).

28. Burges A, Wimberger $\mathrm{P}$, Kümper $\mathrm{C}$ et al. Effective relief of malignant ascites in patients with advanced ovarian cancer by a trifunctional anti-EpCAM $\times$ anti-CD3 antibody: a Phase I/II study. Clin. Cancer Res. 1(13), 3899-3905 (2007).

29. Kitazawa $T$, Igawa $T$, Sampei $Z$ et al. A bispecific antibody to factors IXa and X restores factor VIII hemostatic activity in a hemophilia A model. Nat. Med. 18(10), 1570-1574 (2012).

30. Kotani N, Gu J, Isaji T, Udaka K, Taniguchi N, Honke K. Biochemical visualization of cell surface molecular clustering in living cells. Proc. Natl Acad. Sci. USA 105(21), 7405-7409 (2008).

- Advanced method for detecting bi-molecular complexes on a cell membrane.

31. Hifumi E, Morihara F, Hatiuchi K, Okuda T, Nishizono A, Uda T. Catalytic features and eradication ability of antibody light chain UA15-L against H. pylori. J. Biol. Chem. 283(2), 899-907 (2008).

32. Hifumi E, Honjo E, Fujimoto N, Arakawa M, Nishizono A, Uda T. Highly efficient method of preparing human catalytic antibody light chains and their biological characteristics. FASEB J. 26, 1607-1615 (2012).

33. Hifumi E, Arakawa M, Matsumoto S, Yamamoto T, Katayama Y, Uda T. Biochemical features and anti-viral activity of a monomeric catalytic antibody light chain 23D4 against influenza A virus. FASEB J. 29, 2347-2358 (2015).

- Antiviral activity by a human catalytic antibody light chain.

34. Kou J, Yang J, Lim J-E et al. Catalytic immunoglobulin gene delivery in a mouse model of Alzheimer's disease: prophylactic and therapeutic applications. Molecular Neurobiol. 51, 43-56 (2014).

35. Planque SA, Nishiyama Y, Sonoda S et al. Specific amyloid $\beta$ clearance by a catalytic antibody construct. J. Biol. Chem. 290, 10229-10241 (2015). 